\title{
Políticas sociais em transformação: crianças e adolescentes na era dos direitos
}

\author{
Irene Rizzini \\ Gary Barker \\ Neide Cassaniga
}

\begin{abstract}
RESUMO
Observa-se que, no Brasil, apesar das inovações referentes aos direitos da criança e do adolescente, persistem idéias e práticas antigas que, não garantindo estes direitos, continuam voltadas para situações de emergência, como os programas de atenção aos chamados "meninos de rua". É recente e ainda pouco expressiva a busca de ações preventivas, desenvolvidas em suas famílias e comunidades e voltadas para a proteção, defesa e garantia de seus direitos. Neste texto, é analisada a importância destas ações como um dos meios possíveis de melhorar as oportunidades de vida para a população jovem de baixa renda no contexto urbano, mudando de enfoque, situando a criança na chamada "era dos direitos" e discutindo um sistema que vise o desenvolvimento integral de todas as crianças no Brasil. Palavras-chave: Estatuto da Criança e do Adolescente, prevenção, era dos direitos.
\end{abstract}

\begin{abstract}
In spite of innovations concerning children and teenagers' rights, old practices are still present in Brazil, as these rights are not guaranteed .Only in emergency cases, attention to the so called street boys and girls is given. Actually search for preventive actions is very little; as they are developed in families and communities concerned with these issues. In this paper, the importance of these actions as a way of making living chances for young and poor fellows better in the urban context is analysed ; likewise changing approaches which place children at a time of human rights are also analysed. A system which will thoroughly develop all Brazilian children is discussed.

Key-words: Statute of Children and Teenagers', prevention, right time.
\end{abstract}

\section{Introdução}

Os pressupostos que constituem as bases das políticas sociais destinadas à população jovem vêm mudando de forma significativa nas últimas décadas. Em particular, os anos 80 e 90 apresentaram condições favoráveis a mudanças expressivas de enfoque e ação. A promulgação do Estatuto da Criança e do Adolescente (1990), bem como a participação de diferentes setores organizados da sociedade em defesa dos direitos da criança, constitui parte importante destas mudanças, tornadas possíveis dentro do contexto de redemocratização do país. A Lei de 1990 propõe novos paradigmas de atenção à infância, tomando como base preceitos de garantia de direitos preconizados pela Convenção Internacional dos Direitos da Criança, da qual o Brasil é signatário (NAÇÕES UNIDAS, 1989). O Estatuto estipula normas que visam à proteção da criança com vistas ao seu desenvolvimento integral e conclama a família, o Estado e a sociedade a proverem condições adequadas ao desenvolvimento de todas as crianças e adolescentes, sem qualquer tipo de distinção ou discriminação.

Dentro desta perspectiva, a mudança caminha no sentido de substituir os paradigmas que até então vinham orientando políticas e ações sociais. Repudiam-se as práticas assistencialistas, estigmatizadoras e segregadoras que sustentaram por muitas décadas a divisão entre "crianças" e "menores". Procura-se redefinir os grupos sobre os quais as políticas devem incidir. $\mathrm{Na}$ realidade, esses grupos não mudaram: continuam sendo os mais vulneráveis aos efeitos da pobreza e da exclusão social e os que representam algum tipo de ameaça à sociedade - o que é incompatível com as propostas de garantia de direitos em curso (RIZZINI; BETTEGA; SILVA, 1998). 
Pode-se citar como um exemplo atual o caso dos "meninos de rua". Nos últimos quinze anos aproximadamente, este grupo constitui um dos principais focos de interesse de pesquisa e ação social, tendo mobilizado fortemente a opinião pública internacional. Apesar da importância indiscutível do tema, as crianças e adolescentes que sobrevivem nas ruas representam apenas uma pequena porcentagem de todos aqueles que necessitariam de apoio para que efetivamente desenvolvessem seus potenciais. Quase a metade dos 60 milhões de crianças e jovens brasileiros (até os 17 anos) nasce em famílias pobres, as quais encontram dificuldades em prover cuidados básicos adequados para seus filhos.

Observa-se no presente maior preocupação em melhorar a situação das "crianças de rua", criando-se uma diversidade de programas que visam atender às suas necessidades. Porém, pouco se tem feito no sentido preventivo, evitando que as crianças continuem migrando para as ruas. Embora exista uma consciência crescente da importância deste tipo de ação, ela ainda não é prioritária. O maior desafio é, sem dúvida, atingir o contingente muito maior de crianças e adolescentes de baixa renda que continuam vivendo com as famílias, mas necessitam de apoio para que se desenvolvam de forma adequada.

Uma proposta relativamente comum em diversos países para fortalecer os vínculos da criança em seu próprio contexto é a de desenvolvimento de programas comunitários, cuja idéia é, em síntese, investir nos recursos que cada comunidade dispõe para cuidar de suas crianças. Essa não é uma linha forte de ação social no Brasil, porém, há alguns exemplos emergindo em diferentes estados. Uma das tendências interessantes dos programas criados mais recentemente tem sido a de procurar mudar a ênfase dada aos déficits e problemas das crianças, para depositá-la no desenvolvimento de seus potenciais. A idéia é apoiar as famílias e demais responsáveis pelas crianças, através de programas comunitários, formando-se uma rede de suporte em torno de cada criança.

Neste texto, será analisada a importância de tal tendência como um dos meios possíveis de melhorar as oportunidades de vida para a população jovem de baixa renda no contexto urbano.

\section{Mudança de foco: das crianças de rua para todas as crianças}

Ao longo dos anos oitenta e noventa, as mídias nacionais e internacionais, bem como as organizações locais e internacionais de direitos humanos, têm dado considerável destaque ao problema dos 'meninos de rua' no Brasil, particularmente no que se refere à violência contra estas crianças e atrocidades cometidas por grupos de matadores e pela polícia.

Os 'meninos de rua' têm constituído a imagem ou símbolo da questão da pobreza e da injustiça social no Brasil. Mas será que esta imagem é precisa? Mais importante, será que esta imagem não vem justamente a distorcer o verdadeiro problema na medida em que focaliza apenas aqueles que são mais visíveis e incomodam mais? Há milhões de crianças cujas condições subumanas de vida constituem o exemplo mais flagrante da pobreza e descaso por parte do país, a maior parte das quais vive com suas famílias.

Não há dúvida de que as crianças que sobrevivem nas ruas apresentam necessidades agudas e precisam de cuidados urgentes. As organizações governamentais, não-governamentais e todos aqueles que atuam junto a este grupo vêm desenvolvendo um trabalho vital que ajuda milhares de crianças e adolescentes que precisam de apoio imediato. O que se está propondo é uma mudança de foco no sentido de se formular políticas e se implantar programas que levem em consideração todas as crianças e adolescentes. Todos aqueles, cujos elos com seus pais, familiares e comunidades ainda não tenham se deteriorado e rompido; que estejam envolvidos em suas comunidades, mas que necessitam de suporte para lá permanecerem. Faz-se referência aqui a formas de apoio que favoreçam o desenvolvimento das crianças, ou seja, fortalecimento dos recursos já existentes e outros a serem criados nas comunidades para que possam oferecer segurança, relações afetivas estáveis, cuidados e atenção adequados, oportunidades para desenvolverem suas habilidades, amizades e autoconfiança. Em síntese, trata-se do estabelecimento de condições que contribuam para o desenvolvimento integral de cada criança, como há várias décadas se pleiteia internacionalmente como direito de todas as crianças e adolescentes.

Além dos casos mencionados de indiscutível urgência, nos quais uma política pública de assistência é indicada, há que se pensar no estabelecimento de políticas sociais básicas consistentes para a população jovem do país, permitindo que todos tenham acesso a serviços de qualidade para garantir a sua boa formação, tanto física quanto psicológica. O Estatuto da Criança e Adolescente, a Convenção das Nações Unidas sobre os Direitos da Criança e um corpo volumoso de teorias e pesquisas no campo do desenvolvimento infantil 
apoiam a noção de que as crianças e adolescentes precisam de cuidados adequados e oportunidades para se desenvolverem de forma integrada e harmoniosa.

Estas idéias sobre oportunidades iguais para todas as crianças e adolescentes podem parecer uma utopia, principalmente no caso do Brasil e da América Latina, em virtude das limitações do orçamento público e das privações por que passam grande parte de sua população. A história do continente latinoamericano é marcada por algumas das formas mais brutais de violação de direitos humanos, que vão desde o desrespeito às culturas nativas à imposição de valores, crenças e costumes. É uma história caracterizada por injustiças e desigualdades, que têm permitido muitos privilégios a uma pequena parcela da população às custas do sacrifício da maioria. Cada jovem que é visto desperdiçando o seu potencial nos países deste continente reflete esta história de profunda falta de humanidade.

Não se está falando de uma utopia, mas identificando mudanças em curso. Muitos projetos de parcerias entre os setores público e privado vêm caminhando nesta direção, ao implantar redes de suporte comunitário em diferentes países da região. Acredita-se que esta tendência poderá abrir caminhos para novas propostas que valorizem os potenciais e as competências das crianças e invistam adequadamente em sua formação.

Em outras palavras, trata-se de uma mudança de enfoque, situando a criança na chamada "era dos direitos". O Estatuto da Criança e do Adolescente refere-se aos direitos básicos de todas as crianças, inclusive direitos concernentes à convivência familiar e comunitária e ao lazer como parte fundamental de sua socialização e de seu florescimento enquanto ser humano. Entretanto, este aspecto da legislação não recebe ainda a devida atenção.

Neste sentido, a incorporação da noção de direitos individuais e de cidadania, de acordo com as normativas nacional e internacional, requer a transformação de paradigmas e valores presentes nestas sociedades. A contribuição dada aqui para este debate consiste em discutir as mudanças e as tendências que estão em curso, com a consciência do fato de que existem interesses, profundamente enraizados na sociedade, contrários às noções de igualdade, direitos, cidadania e justiça social.

\section{Em busca de melhores oportunidades para todas as crianças e adolescentes}

Para muitas organizações governamentais e não-governamentais que atuam na área social no Brasil, os 'meninos de rua' passaram a representar, nos anos 80, o símbolo de um dos piores exemplos de exclusão social e uma causa pela qual lutar. Embora não se tenha como objetivo fazer uma análise exaustiva dos programas voltados para este grupo, considera-se importante examinar a forma pela qual se desenvolveram, bem como seu impressionante legado em termos dos esforços empreendidos de advocacia, pesquisa e metodologia. Vale a pena destacar alguns aspectos dos referidos programas, particularmente aqueles que oferecem algumas pistas sobre as possibilidades de expandir as iniciativas já existentes para se atingir todas as crianças.

A preocupação com as crianças de rua, sobretudo com o aumento aparente no número de crianças trabalhando e morando nas ruas do país no decorrer dos anos 80 , conduziu à criação de inúmeras organizações com o propósito de ajudá-las. Entre estas, está o Movimento Nacional de Meninos e Meninas de Rua, uma rede nacional dedicada à advocacia e ao treinamento dos chamados educadores de rua. Um grande número de projetos veio ao encontro das crianças, procurando atender as suas necessidades e denunciando as situações de descaso e violência das quais eram vítimas.

Uma das lições mais importantes que se aprendeu com a experiência do Movimento Nacional e dos programas destinados às crianças nas ruas foi a ênfase dada à capacidade das crianças em serem os agentes de seu próprio desenvolvimento, ou os agentes de mudança nas próprias vidas (MYERS, 1988). No lado negativo, alguns programas para crianças de rua reforçaram a imagem das crianças como pequenos heróis, exaltando sua coragem e subestimando o sofrimento e a solidão que tinham que suportar. Contudo, a maior parte dos programas efetivamente procurou oferecer opções para as crianças, reconhecendo que a grande maioria tinha poucas possibilidades além da luta pela própria sobrevivência. Assim, a base dos programas que obtiveram reconhecimento ao longo dos anos foi a de ajudar as crianças a refletirem sobre sua própria vida e outras alternativas de vida.

Outro legado importante dos programas destinados aos 'meninos de rua' foi o desenvolvimento de uma filosofia e metodologias para se trabalhar com as crianças e jovens nas ruas, inclusive com ensinamentos baseados em Paulo Freire. Os chamados 'educadores de rua', que se especializaram para ajudar estas crianças, geralmente serviam como o primeiro ponto de contato entre as crianças e as organizações que ofereciam 
apoio. Isso era importante, pois os educadores de rua representavam a primeira tentativa de se organizar e profissionalizar uma intervenção junto a estas crianças no Brasil e serviu de modelo para vários outros países (CASTRO, 1997; CHALHUB, 1997).

Os Programas voltados para as crianças de rua no Brasil também se destacaram por sua flexibilidade e criatividade no trato com as crianças, respeitando suas características específicas e adaptando os programas às crianças ao invés de obrigar as crianças a se ajustarem aos programas. Neste sentido, eles eram totalmente diferentes dos programas tradicionais de assistência à infância e do sistema de ensino público no Brasil, cuja tendência era exatamente a oposta.

Observa-se que o Brasil também exerceu uma certa liderança internacional no que se refere à produção de conhecimento. Existe uma vasta literatura abordando a situação e as necessidades das crianças que vêm sobrevivendo nas ruas, a qual possibilitou uma melhor compreensão de vários aspectos de suas vidas. Esta produção também contribuiu como base para a criação de programas especializados para o atendimento a estas crianças e jovens.

Todo esse esforço deve ser reconhecido como um passo importante, pois representou um amplo movimento sem precedentes na história do Brasil, com a participação de diversos segmentos da sociedade na luta em defesa da criança. Em décadas anteriores, muitas destas crianças estariam fadadas a passarem sua infância enclausuradas em instituições para menores. Contudo, há de se argumentar que o foco sobre os meninos de rua, assim como os projetos voltados para eles atingem apenas uma pequena parcela da população que necessita de apoio e não resolvem o problema, pois é mínimo o impacto que causam sobre as vidas de milhões de crianças que se encontram à margem da sociedade (MYERS,1991).

Nos últimos anos, parece haver um reconhecimento crescente, nas instituições que atuam junto a este grupo, de que é necessário ampliar o escopo de ação para incorporar as crianças que ainda não estão vivendo ou trabalhando nas ruas, mas que possivelmente serão levadas a isso caso nada seja feito para evitá-lo. Buscam-se, neste sentido, formas alternativas de prevenção que atuem enquanto as crianças ainda estão ligadas às suas famílias e comunidades, em particular nos casos em que a criança corre o risco eminente de abandonar a escola e ser iniciada nas ruas.

É importante destacar que, apesar desta tendência (de priorizar a prevenção) estar se tornando cada vez mais presente, ela ainda é extremamente limitada em termos concretos. Na realidade, são poucos os programas essencialmente comunitários existentes no Brasil e na América Latina como um todo. Pouco se fez no sentido de atuar junto às comunidades de onde as crianças saem com mais freqüência, evitando que entrem no mundo da rua. Outra lacuna fundamental tem sido a falta de apoio em termos de programas voltados para apoiar diretamente os pais ou responsáveis pelas crianças desde o seu nascimento para que tenham melhores condições de oferecer os cuidados de que necessitam para um crescimento saudável.

Pode-se dizer que a noção de prevenção ainda não está plenamente enraizada no Brasil. No caso específico aqui retratado, ou seja, a prevenção no sentido de se evitar que as crianças acabem nas ruas, implica em mudanças ao nível macro da sociedade, incluindo-se a melhoria das condições de vida para a população, reforma do sistema formal de educação e saúde e mudanças nos sistemas econômicos que vêm mantendo milhões de famílias em situação de pobreza e marginalidade. Entretanto, mesmo os países industrializados, nos quais as pessoas têm à sua disposição serviços públicos de melhor qualidade, hoje reconhecem a necessidade de se oferecer serviços adicionais que sirvam de apoio a crianças e jovens, em conexão com o sistema escolar e outros serviços existentes na área social (SHERRADEN, 1992; WHALEN; WYNN, 1995).

\section{Por um sistema de apoio com vistas ao desenvolvimento integral de todas as crianças no Brasil}

Em diversos países da Europa Ocidental, a noção de que todas as crianças e adolescentes merecem especial atenção é hoje aceita, não devido à sua condição financeira ou à sua situação 'de risco', mas sim devido à sua condição de desenvolvimento, exatamente como se lê no Estatuto da Criança e do Adolescente. Reconhecendo a profunda diferença da história social da criança e da família no Brasil e na Europa, pode-se observar como esse tipo de modelo poderia ser pensado para o caso brasileiro.

Uma das questões a se levar em consideração seria se as políticas e os programas sociais deveriam direcionar recursos e energia à prevenção de problemas ou diretamente à promoção de suporte visando o desenvolvimento integral de todas as crianças e jovens. A tendência, já explicitada na legislação nacional e na normativa internacional, é de se gerar condições mais adequadas ao desenvolvimento integral de todas as 
crianças. Cabe, portanto, explorar que tipo de suporte se necessita e por onde começar. Um ponto de partida natural seria incluir os pais e/ou demais responsáveis, bem como as próprias crianças e adolescentes no processo de identificação dos tipos de apoio a serem priorizados. Qualquer pessoa, independente de seu nível educacional e econômico, saberá dizer o que gostaria para seus filhos e chegar a um consenso junto com a comunidade do que seria mais importante focalizar.

Trabalhar junto aos pais como estratégia para se definir onde e como investir é uma idéia interessante e muito pouco usual nos segmentos pobres da sociedade, onde têm predominado as intervenções assistencialistas, impostas de forma arbitrária e autoritária. Uma maneira de explorar esta questão é tomar como exemplo o caso da população de rendas média e alta no Brasil. Uma família de classe média ou alta normalmente assegura que seus filhos obtenham uma educação de boa qualidade, colocando-os em escolas particulares. A saúde também é coberta, fugindo-se dos baixos padrões públicos, por meio de agências de seguro, cujos preços são proibitivos, até mesmo para parte das classes médias hoje. Além disso, sabe-se que a escola sozinha não é capaz de oferecer uma educação mais completa às crianças; portanto elas são engajadas numa variedade de cursos particulares, que vão desde a complementação educacional das crianças (cursos de idiomas, computação etc.) até atividades culturais, recreativas e esportivas (dança, música, artes, natação, karatê etc.). Caso a criança apresente algum tipo de problema, há uma série de profissionais a serem acionados, entre psicólogos, fonoaudiólogos, fisioterapeutas etc. É importante notar que a principal preocupação destes pais não é evitar que seus filhos venham a ter problemas ou "se meter em encrencas", mas a de promover um desenvolvimento mais integrado e a felicidade de seus filhos.

O que se deseja destacar aqui é que a típica família de classe média brasileira normalmente lança mão de recursos financeiros para prover uma multiplicidade de complementos à educação e formação de seus filhos. São, na verdade, luxos ou privilégios, que as crianças mais pobres não têm acesso, a não ser de forma muito modesta ou quando oferecidos por instituições filantrópicas. Não que seus pais não desejassem envolver seus filhos, mas essa possibilidade simplesmente não existe por falta de recursos.

Sabe-se que em hipótese alguma isso é suficiente para o desenvolvimento integral de uma criança tais atividades devem ser vistas como realmente são, nada mais que complementos que enriquecem a vida de uma criança. Para que ela possa se beneficiar e apresentar os resultados esperados, é preciso que tenha condições emocionais que permitam um desenvolvimento efetivamente harmonioso.

Outra questão a ser levada em conta nesta discussão é o problema da alocação de recursos. O argumento tradicional é que faltam recursos e que é preciso, portanto, empregá-los junto aos mais necessitados. Este é sem dúvida um argumento válido, que também se aplica no caso do uso de recursos destinados a dar suporte às crianças. As verbas públicas devem ser prioritariamente empregadas com aqueles que não dispõem de recursos. O risco implícito neste tipo de visão é a conhecida falta de compromisso político, levando à criação de redes de serviços diferenciados para os mais pobres e os mais bem posicionados socialmente. Pode-se imaginar esse quadro se perpetuando no Brasil, no caso em que fique estipulado que o governo financiaria redes de suporte ao desenvolvimento somente das crianças pobres. Ou seja, nada mudaria.

Ao se examinar as experiências provenientes da América do Norte e da Europa Ocidental, depreendese que o compromisso político existente para se assegurar redes de apoio para crianças e jovens é mais profundo e contínuo quando envolve igualmente as classes médias. O que acaba acontecendo é que a qualidade destes serviços é melhor (ou mais próxima daquela oferecida pelo setor privado), pois as famílias de classe média têm mais poder para garantir a boa qualidade dos serviços e, na verdade, só permitirão que seus filhos participem de programas públicos se a qualidade for compatível com aquilo que puderem obter no setor privado (mesmo pagando com dificuldade).

Um problema de extrema gravidade para o qual a sociedade brasileira parece pouco atenta é o processo crescente de segregação social que se está vivendo. A despeito dos avanços assinalados em termos do debate sobre cidadania e direitos, os mundos e as realidades nos quais vivem os pobres e os ricos parecem cada vez mais distantes. As cidades vão se tornando mais segregadas, com espaços de lazer, recreação, cultura, educação etc., diferentes para pobres e ricos. A questão é ainda mais complexa ao envolver a população jovem. Crianças e adolescentes têm cada vez menos oportunidades de encontro, convivência e interação.

As conseqüências deste tipo de tendência ainda não foram exploradas, porém elas já se mostram visíveis em termos da hostilidade identificada entre diferentes grupos. Um dos exemplos mais gritantes é o de crianças das classes médias que não saem de seus condomínios com medo de usar transporte público e se defrontar com os "pivetes", os "trombadinhas" ou os "meninos de rua". Não é difícil imaginar os problemas que advirão deste "estranhamento" entre crianças que, na verdade, estariam se beneficiando em muitos sentidos da troca com seus pares de origens tão diversificadas culturalmente. 


\section{Mudanças em curso: possíveis caminhos}

O momento atual favorece o entendimento mais amplo da situação da infância como estando associada a uma série de outras questões de ordem política, econômica e social, assim como a fatores estruturais e conjunturais que permitem a manutenção da fantástica desigualdade social, que ainda caracteriza este país.

As mudanças em curso são parte de transformações globais mais abrangentes que conduzem à diminuição radical da intervenção do Estado na área de assistência social e levam à necessidade de reavaliação das políticas sociais. Estas tendem a ser mais descentralizadas e autônomas, buscando-se uma cogestão entre governo e sociedade civil. Dada a herança histórica de tantos países latino-americanos, subjugados às potências que dividem o poder e os lucros, a parceria governo-sociedade civil é uma experiência recente e muito difícil. Ela, porém, possibilita uma nova gama de alternativas que implicam em maior participação das comunidades onde os órgãos responsáveis pelas políticas e programas atuam, incentivando o desenvolvimento de um sentido de cidadania sem precedentes na história até o presente.

Dentro deste quadro, substituem-se os paradigmas que vinham orientando políticas e ações no campo social destinadas à população jovem, repudiam-se as categorias estigmatizadoras e segregadoras que sustentaram por décadas a divisão entre "crianças" e "menores" e procura-se redefinir os grupos sobre os quais as políticas devem incidir. Estes grupos, em sua essência não mudaram: continuam sendo os mais vulneráveis aos efeitos da pobreza e da exclusão social. Entretanto, modifica-se a forma de compreender os problemas e suas demandas, e, consequentemente a forma de prestar assistência.

O conceito de criança em "situação de risco" (pessoal e social) passa a ser utilizado na tentativa de adequar os novos enfoques à realidade atual, reconhecendo-se que as mudanças significativas em geral pressupõem um processo lento e complexo de negociações, ajustes e mudança de mentalidade e atitudes. É fundamental destacar que, neste sentido, a tendência é o fortalecimento da noção de prevenção, priorizando-se ações que diminuam as chances de se intervir quando os problemas tornam-se irreversíveis.

Tendo como foco a meta de promover apoio a todas as crianças, serão apontados, a título de exemplo, alguns dos possíveis caminhos que fortaleceriam o sentido de prevenção e de integração social de crianças e adolescentes que historicamente têm permanecido à margem da sociedade:

\section{Ampliação e reformulação do conceito de "situação de risco"}

Sugere-se englobar nesta categoria, todas as crianças percebidas como vulneráveis e não somente as mais pobres. Isso implica na ampliação e na reformulação do conceito de risco. Estão em situação de risco, por exemplo, todas as crianças que estão hoje encontrando nas ruas uma alternativa de vida; aquelas que estão fora da escola ou tendo dificuldades de nela permanecer, aquelas oriundas das classes mais abastadas, mas que apresentam problemas, cometem infrações etc. As crianças que necessitam de apoio para além daquele que seus pais podem oferecer são facilmente identificáveis no âmbito da própria família, da vizinhança e de grupos atuantes junto à população em cada comunidade.

\section{Deslocar o foco: das deficiências para os potenciais}

A história da assistência à infância no Brasil revela que a ênfase tem sido sobre deficiências, desvios e problemas relacionados às crianças, criando-se categorias que as estigmatizaram e impediram 0 desenvolvimento de um sentido de cidadania. Nesta linha, foram criadas políticas públicas paliativas e serviços de baixa qualidade para os pobres, que contribuíram para acirrar as desigualdades sociais. Além disso, no que se refere aos principais responsáveis pelas crianças, a orientação que prevaleceu foi a de retirar as crianças de seus lares/comunidades em detrimento de programas de apoio aos pais para que pudessem cuidar de seus filhos.

Se deseja-se combater estas tendências e disparidades, há que se investir nos potenciais, tanto das crianças quanto de seus pais, valorizando-se o fortalecimento dos laços parentais. Antes que uma criança possa se transformar em um cidadão, ela precisa de condições favoráveis para desenvolver seu sentido de pessoa (de EU). Isso só é possível através do estabelecimento de um sentido de confiança básica, como diria Erik ERIKSON (1963), autor do clássico "Infância e Sociedade” . É esse sentido de confiança, vital para todo o desenvolvimento de um ser humano, que lhe dá a consciência de pertencer ao mundo. A criança adquire (ou não) essa confiança através do estabelecimento de elos afetivos com a mãe antes mesmo de seu nascimento, e ela vai se fortalecendo nas relações com todas as outras figuras significativas em sua vida. 
3. Apoio aos responsáveis e demais envolvidos no cuidado às crianças

É exatamente o cuidado oferecido à criança em seu dia-a-dia que torna (ou não) possível o desenvolvimento integral de seus potenciais e o crescimento harmonioso que permitirá a sua integração à vida em sociedade.

Recomendam-se formas de fortalecimento dos elos estabelecidos com as crianças, por meio do apoio prestado no âmbito das famílias e das comunidades. Aqui, novamente, a identificação de onde e como atuar pode ser facilitada com a participação de grupos nas próprias comunidades. A idéia é incentivar as estruturas de apoio já estabelecidas ou então criar estruturas de apoio onde não existirem. É importante estabelecer parcerias com instituições e grupos que vêm desenvolvendo ações de apoio nas comunidades, como as escolas, igrejas, associações de moradores, ONGs etc.

Seria interessante a implementação de projetos que servissem de piloto em comunidades onde um grande número de crianças se encontra à caminho das ruas. Esta seria na prática uma proposta de mudança de enfoque, enfatizando-se a dimensão preventiva.

4. Mudança de mentalidade e de atitudes

O que se está propondo aqui é essencialmente estimular uma mudança de mentalidade e de atitudes, hoje em pleno curso, como de fato demandam os paradigmas atuais de cidadania e respeito aos direitos humanos.

Quais seriam alguns dos possíveis caminhos? Novamente, a título de exemplo, são citados os seguintes

- acreditar na criança (investir nas suas competências, em todos os seus potenciais);

. "resgatar" a família (idem, modificar a atitude de ressaltar deficiências/fracassos);

- formar redes de apoio e de solidariedade. Estabelecer formas de apoio aos pais (ou pais substitutos) e à comunidade (investir nos elos antes que se deteriorem e se rompam);

- despertar, sensibilizar e capacitar as pessoas para conduzir estas mudanças (todos aqueles que lidam com as crianças devem ter a oportunidade de ampliar e aprofundar seu conhecimento para terem melhores condições de exercer seus papéis de formadores de gerações de crianças: pais, professores, educadores sociais etc.).

Essas mudanças vão na mesma direção que as apontadas anteriormente. Em seu nível mais profundo, elas implicam em rever valores e práticas que são predominantes na sociedade, procurando-se outros referenciais que orientem os adultos na formação das gerações atuais para que melhor se integrem socialmente e estejam mais preparadas para os desafios a serem enfrentados.

\section{REFERÊNCIAS}

ADORNO, S. Children in Brazil: legislation and citizenship. In: RIZZINI, I. (Ed.). Children in Brazil today: a challenge for the third millennium. Rio de Janeiro: EDUSU, 1994.

BARKER, G. Assisting at-risk urban youth in Northeast Brazil: a project to prevent delinquency, abandonment and child prostitution. Brasilia: U.S. Agency for International Development (unpublished report), 1994.

. Integrated service models for youth: an analysis of selected international experiences. Washington : World Bank (unpublished working paper), 1996.

; FONTES, M. Review and analysis of international experience with programs targeted on at-risk youth. Washington: World Bank/Working Paper n. 5, 1996.

; KNAUL, F. Exploited entrepreneurs: street and working children in developing countries. New York: Childhope-USA/Working Paper n. 1, 1991.

BLACK, M. Street and working children. INNOCENTI GLOBAL SEMINAR (1993: Florence). Summary Report. Florence: UNICEF, 1993.

BOYDEN, J.; HOLDEN, P. Children of the Cities. London: 1991.

BRUCE, J. et al. Families in focus : new perspectives on mothers, fathers, and children. New York: Population Council, 1995. 
CARVALHO, M. A. C. de. Street pedagogy: principles extracted from a practical analysis. In: INTERNATIONAL SEMINAR ON LEARNING (1992: Porto Alegre). Paper... Porto Alegre, 1992.

CASTRO, M. R. de. Retóricas da rua : educador, criança e diálogos [Street rethorics : the educator, the child and dialogues]. Rio de Janeiro: EDUSU/AMAIS, 1997.

CENTER FOR POLICY STUDIES IN EDUCATION, FLORIDA STATE UNIVERSITY. Asserting the education rights of street and working children: lessons from the field. Tallahassee, Florida, 1994.

CHALHUB, T. Homeless children in Rio de Janeiro : Exploring the Meanings of Street Life. Children \& Youth Care Forum, New York, v. 26, n. 3, June 1997.

DEWEES, A.; KLEES, S. J. Social movements and the transformation of national policy : street and working children in Brazil. Comparative Education Review, v. 39, n. 1, Feb. 1995.

ECA em Revista [The Statute of the Child and Adolescent]. São Paulo. April/May/1997.

ENNEW, J.; MILNE, B. The next generation - Lives of the third world children. London: Zed Books Ltd., 1989.

ERIKSON, E. Childhood and Society. New York: W.W. Norman \& Company, 1963.

FAUSTO, A.; CERVINI, R. O trabalho e a rua: crianças e adolescentes no Brasil urbano in the 1980's (Work and Street : Children and Adolescents in Urban Brazil in the 1980s). São Paulo: Cortez, 1991.

FLOREZ, C.; KNAUL, F.; MENDEZ, R. Un analysis cuantitativo del trabajo infantil y juvenil en Colombia [A quantitative Analysis of Child Labor in Colombia]. Desarrollo y Sociedad, v. 34, set. 1994.

GAMBONE, M.; ARBETON, A. Safe havens: The contributions of youth organizations to healthy adolescent development. Philadelphia, PA: Public/Private Ventures, 1997.

IBGE/UNICEF [Brazilian Institute of Geography and Statistics] (1997). Indicadores sobre crianças e adolescentes [Indicators on Children and Adolescents]. Brasília, Rio de Janeiro.

MYERS, W. Alternative services for street children: the brazilian approach. In: BEQUELE, A.; BOYDEN, J. Combating child labour. Geneva: International Labour Office, 1988.

(Ed.). Protecting working children. London: Zed Books/UNICEF, 1991.

NETO, P. Reform and social development project: evaluation of the program Living and Learning - ABC Community Project. Fortaleza, 1994. Unpublished.

OLIVEIRA, J.S. (Org.). O traço da desigualdade social no Brasil [Social inequality in Brazil]. Rio de Janeiro: IBGE, 1993.

PESQUISA muda teses sobre meninos de rua [Study changes theses on street children]. Jornal do Brasil, Rio de Janeiro, 17 maio 1995.

PILOTTI, F.; RIZZINI, I. (Ed.). A arte de governar crianças: a história das políticas sociais, da legislação e da assistência à infância no Brasil [The art of governing children: the history of social policies, legislation and child welfare in Brazil]. Rio de Janeiro: Instituto Interamericano del Niño/CESPI/USU/AMAIS, 1995.

PITTMAN, K.; CAHILL, M. A new vision: promoting youth development. Washington, DC/New York: Center for Youth Development and Policy Research/Academy for Educational Development (Commissioned Paper \#3), 1991.

PROJETO AXE. Meninos que vivem nas ruas de Salvador - Mapeamento e contagem [Children living in the streets of Salvador - Mapping and counting]. Salvador, Bahia (Unpublished mimeog), 1993.

RIBEIRO, R.; SABÓIA, A. L. Children in Brazil: Legislation and citizenship. In: RIZZINI, I. (Ed.). Children in Brazil today: a challenge for the third millennium. Rio de Janeiro: EDUSU, 1994.

RIZZINI, I. O século perdido: raízes históricas das políticas públicas para a infância no Brasil [The lost century: the historical roots of public policies for children in Brazil]. Rio de Janeiro: EDUSU/AMAIS, 1997a.

.(1997b). Childhood and national identity. Paper presented at the urban childhood conference. The Norwegian Centre For Child Research. Trondheim, Norway.

. Poor children in Latin America: a case example of social inequality. Children's Legal Rights Journal, Chicago, v. 18, n. 1, 1998a. 
. (Ed.) Deserdados da sociedade: os "meninos de rua" da América Latina [Disinherited from society: "street children" in Latin America]. Rio de Janeiro: CESPI/USU, 1995.

et al. Childhood and urban poverty in Brazil: Street and working children and their families. Florence, Italy:



.; BARKER, G., CASSANIGA, N. From street children to all children. improving the opportunities of low income urban children and youth in Brazil. In: THE JOHANN JACOBS CONFERENCE (1998d). Lake Constance, Germany, 1998d.

.; BARKER, G. One step forward, two steps back: children and youth in the face of change in Brazil. South Carolina: Childwatch International, 1998b. Mimeog.

; BetTeGA, M. O.; SILVA, P. V. B. da. Criança, adolescente e integração social. Curitiba: Secretaria Municipal da Criança (Geprocari), 1998c. Mimeog.

SALES, M. A.; ALENCAR, M. M. T. de. O Estatuto da Criança e do Adolescente e a Política Social para a Infância e Juventude. Em Pauta, Rio de Janeiro, n. 11, 1997.

SCHNIEDMAN, M. Targeting at-risk youth: rationales, approaches to service delivery and monitoring and evaluation issues. Washington, DC: World Bank (Unpublished mimeog.), 1996.

SECRETARIA DE AÇÃO SOCIAL. Report on census of street and working children. Fortaleza: Secretaria Estadual (Ceará) de Ação Social [State Social Action Secretary], 1994.

SHERRADEN, M. Community-based youth services in international perspective. Washington, DC: Carnegie Council on Adolescent Development, 1992.

STEPHENS, S. Children and the politics of culture. New Jersey: Princeton University Press, 1995.

UNDP Report (1993, 1994).

UNICEF. Situation analysis-country programme 1994 -2000. Children and adolescents - Right to have rights. Brasília: UNICEF, 1993.

WHALEN, S.; WYNN, J. Enhancing primary services for youth through an infrastructure of social services. Journal of Adolescent Research, v. 10, n. 1, Jan. 1995.

WORLD BANK. World development report 1997: the state of a changing world. New York: Oxford University Press, 1997. 